\title{
The absorption and distribution of the naturally occurring tocochromanols in the rat
}

\author{
By C. K. PEARSON AND M. MCC. BARNES \\ Department of Biochemistry, University of Liverpool \\ (Received 13 November 1969-Accepted 10 December 1969)
}

\begin{abstract}
I. Groups of female albino rats were given $12-20 \mathrm{mg}$ of one of the eight known tocochromanols in $0 \cdot 2 \mathrm{ml}$ arachis oil by stomach tube, and were killed $2,4,8,16$ or $24 \mathrm{~h}$ afterwards. The liver, spleen, heart, kidneys, brain, small intestine and a portion of striated muscle were removed from each rat and analysed for the tocochromanol given.

3. Maximum levels of the tocochromanols occurred in most tissues $4^{-8} \mathbf{~ h}$ after dosing. In the liver the tocopherols were more efficiently absorbed than were the corresponding tocotrienols. In kidney, heart and muscle the percentage uptake of the tocotrienols was often greater than that of the corresponding tocopherols.
\end{abstract}

There are eight known naturally occurring tocochromanols. A good deal of information exists concerning the relative biological potencies of four of these, the tocopherols, but only fragmentary knowledge is available concerning the tocotrienols (Bunyan, McHale, Green \& Marcinkiewicz, I96r). The results of tests involving oral dosing show that the relative order of potency is: trimethyl $>$ dimethyl $>$ monomethyl tocol.

Results of tissue storage tests (summarized by Bunyan et al. 196r) show that the tocopherols are stored in the tissues examined (liver, fat and hen's eggs) in the relative order of their potencies by gestation-resorption assay. These findings indicate that the widely differing potencies of the tocopherols may be due to their differential absorption by the intestine. However, when the intestine is by-passed as in the liverslice respiration test in which tocopherol is injected directly into the portal vein (Green, Edwin, Bunyan \& Diplock, I960), similar differences in the order of biological potency are obtained. This would appear to indicate that intestinal absorption is not alone in determining biological activity. The tissue in which the tocochromanol functions may also exhibit a selective action and the type of response of the tissue may also be important.

Reports of biological potencies of the tocotrienols are few, but Bunyan et al. (I96I) reported that the potencies of $\zeta_{1}$ and $\epsilon$-tocopherol ( $\alpha$ - and $\beta$-tocotrienol) were less than those of the corresponding saturated compounds. With these factors in mind the absorption of the eight naturally occurring tocochromanols by the rat, and their subsequent distribution in the tissues were studied in order to indicate possible relative biological potencies (Pearson \& Barnes, I968).

\section{EXPERIMENTAL}

Chemicals. Natural D-tocopherols (Distillation Products Industries, Rochester, New York, USA) were used throughout. All the tocopherols were purified before use by preparative thin-layer chromatography to remove unwanted contaminating toco- 
pherols. $\alpha$ - and $\delta$-Tocotrienol were isolated from the latex of Hevea brasiliensis and $\beta$-tocotrienol was isolated from wheat bran. $\gamma$-Tocotrienol was given by Drs Whittle, Dunphy and Pennock of this Department (isolated from Hevea latex).

Animals and diets. Albino female rats weighing about 200-220 $\mathrm{g}$ were used throughout. They were maintained on a food cube diet (Spital no. 4; Silcock \& Lever Feeds Ltd, Bromborough, Cheshire).

Dosing of animals and removal of tissues. A group of rats were starved overnight and the following morning they were given $\mathrm{I} 2-2 \mathrm{O} \mathrm{mg}$ tocochromanol in $0.2 \mathrm{ml}$ arachis oil by stomach tube (see Table r). Only one tocochromanol at a time was given. They were allowed only water ( $a d$ lib.) after dosing and were killed at intervals of 2, 4, 8, I6 or $24 \mathrm{~h}$ after dosing, two or three rats being killed at each time. The rats were killed by chloroform inhalation and the small intestines (from stomach to caecum exclusive), livers, hearts, spleens, kidneys, brains and a portion of skeletal muscle (from the hind legs and lower back) were removed.

The small intestines were slit open longitudinally and the contents rinsed out with water; the hearts were also slit open and the contents rinsed out in a similar manner. The skeletal muscle was dissected further and the nerves and ligaments were removed. The livers, spleens, kidneys and brains were rinsed immediately with water. All tissues after rinsing with water were dried with filter-paper and weighed. In the removal of all the tissues care was taken to dissect away superfluous adipose tissue.

In all experiments the livers were analysed immediately after removal from the rats. The other tissues were stored under nitrogen at $-20^{\circ}$ until required.

Estimation of tocochromanols. Tocochromanols were estimated by a modified procedure of that reported by the Society for Analytical Chemistry: Analytical Methods Committee (1959). Total lipid was extracted from the tissues by the method of Albrink (1959-60). The lipid was saponified with sodium hydroxide (160 g/ $100 \mathrm{ml}$ water) in the presence of $5 \%$ ethanolic pyrogallol as antioxidant. The non-saponifiable material was extracted into diethyl ether and subsequently chromatographed on columns of Decalso F (The Permutit Co. Ltd). To elute all the tocochromanol $100 \mathrm{ml}$ $35 \%$ diethyl ether-light petroleum (b.p. $40-60^{\circ}$ ) were found to be necessary. Each new batch of Decalso was calibrated before use to find the volume and percentage of diethyl ether in light petroleum which was necessary to elute all the tocochromanol. Final purification of the tocochromanols was obtained by two-dimensional chromatography of the lipid on thin layers of silica gel G (E. Merck A. G., Darmstadt, Germany), using $\mathrm{CHCl}_{3}$ as solvent in the first dimension and $20 \%$ di-iso-propyl ether in light petroleum (b.p. $40-60^{\circ}$ ) in the second dimension. The tocochromanols were detected under ultraviolet light $\lambda 254 \mathrm{~nm}$, after the chromatograms had been sprayed with $0.01 \%$ ethanolic fluorescein solution (Dunphy, Whittle \& Pennock, I965), and the appropriate areas of silica gel were scraped off and the tocochromanols eluted with spectroscopically pure ethanol. The tocochromanols were then determined by the method of Emmerie \& Engel (1938). 

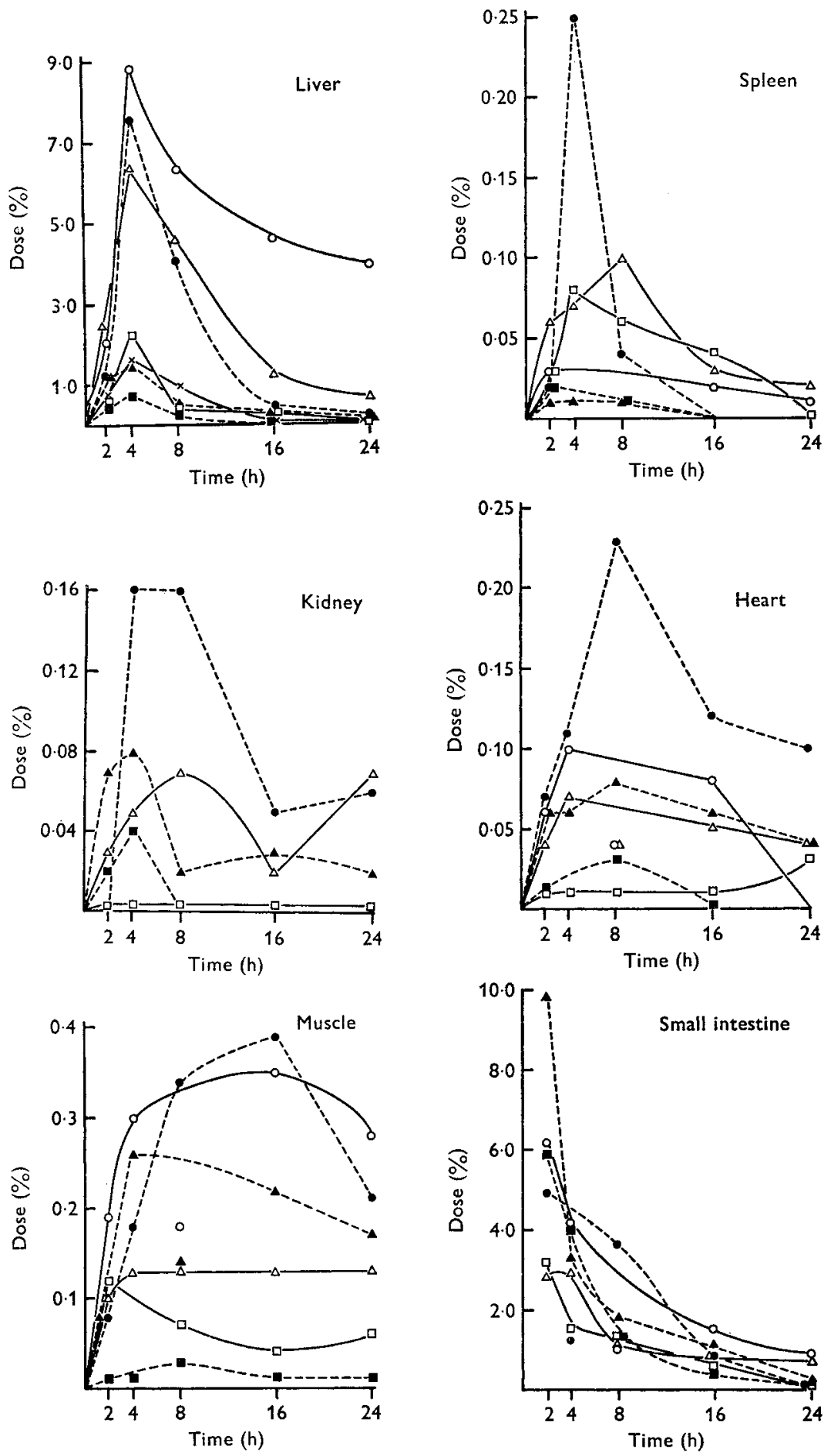

Fig. I. Uptake of tocochromanols by rat tissues $2,4,8,16$ and $24 \mathrm{~h}$ after a single dose of $12-20 \mathrm{mg}$ tocochromanol in $0.2 \mathrm{ml}$ arachis oil given by stomach tube. $\mathrm{O}-\mathrm{O}, \alpha \mathrm{T} ; \Delta-\triangle$, $\beta \mathrm{T} ; \square-\square, \gamma \mathrm{T} ; \times-\times, \delta \mathrm{T} ; \bullet---0, \alpha \mathrm{T}_{3} ; \Delta---\Delta, \beta \mathrm{T}_{3}, \mathbf{\square}---\mathrm{m}, \gamma \mathrm{T}_{3}$. 


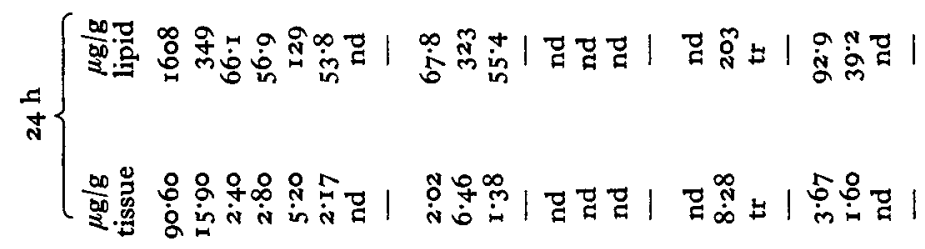

2

के

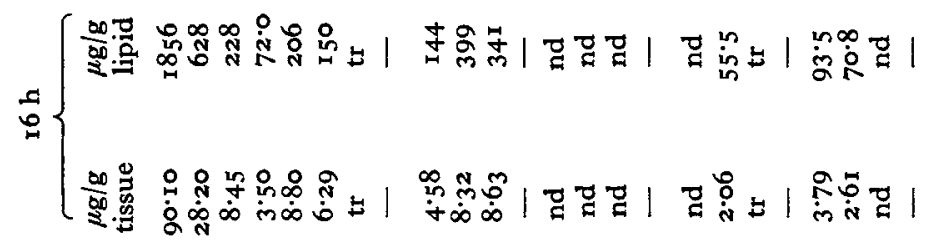

\&

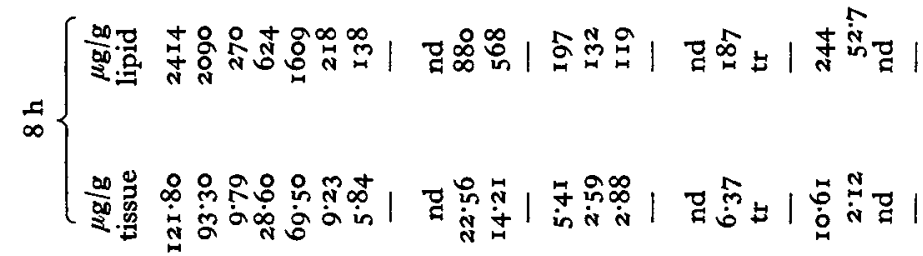

$\infty$ is

$+\overline{8}$

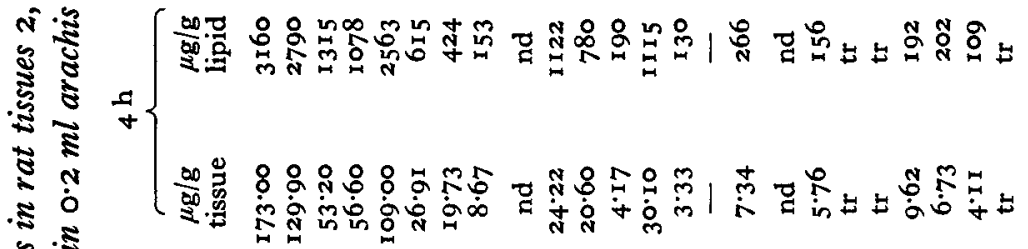

:

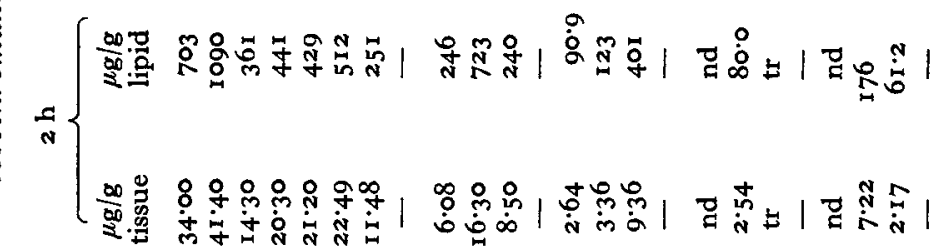

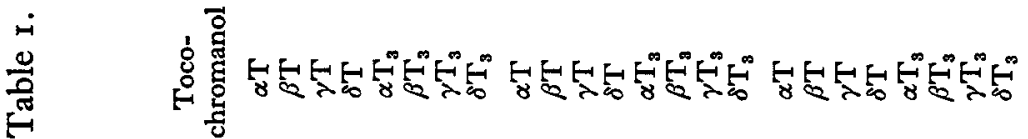

焉

ฐึّ

害 


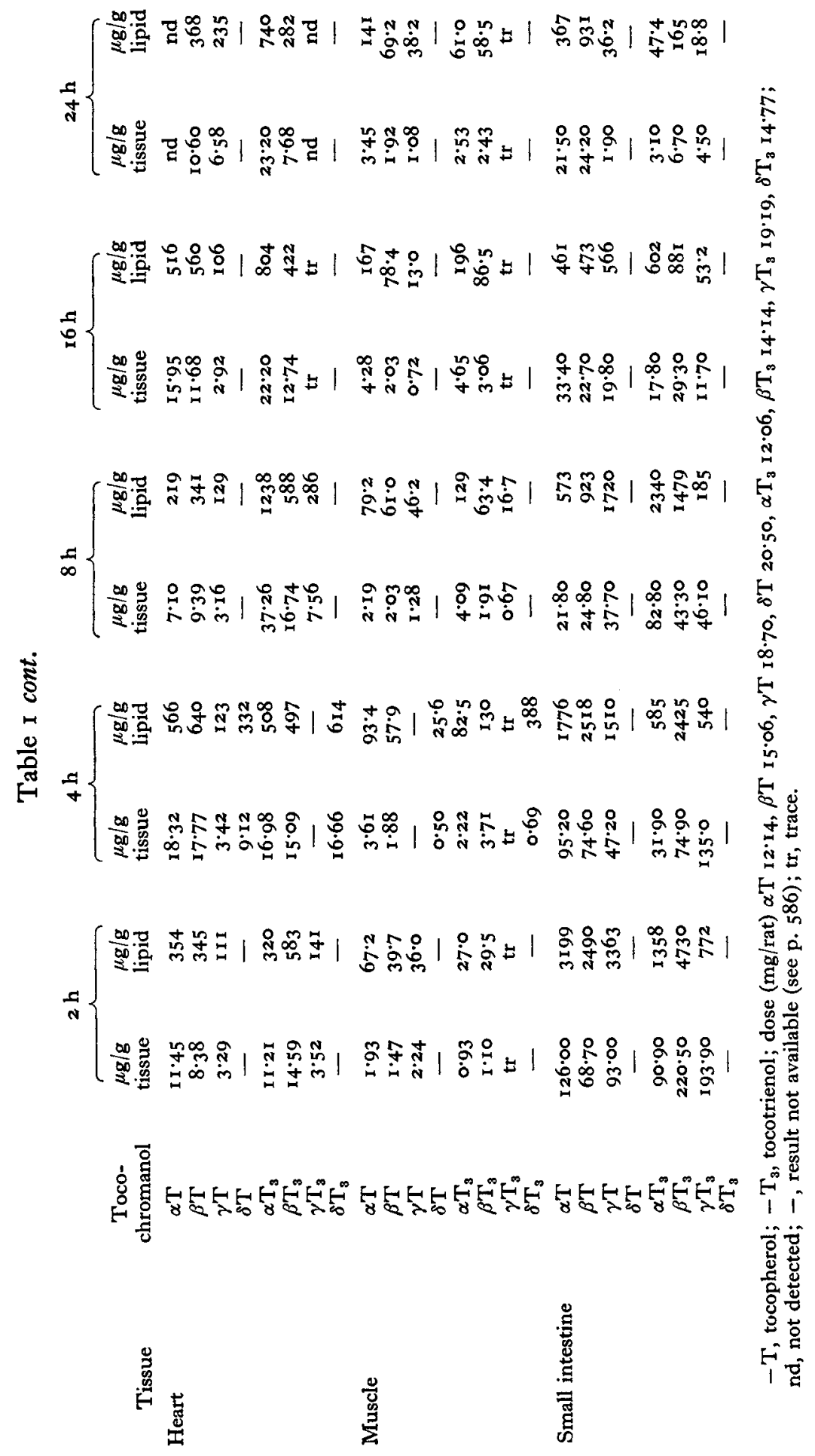


The results, in $\mu \mathrm{g} / \mathrm{g}$ tissue, are summarized in Table $\mathrm{I}$ and in Fig. I and they show the relative uptake by different tissues. The tissues of the rats normally contained $\alpha$-tocopherol, but in relation to the dose given only the liver contained a significant amount $(\sim 0.4 \%$ dose). The liver usually contained a higher concentration of dosed tocochromanol than the other tissues; however, more was sometimes found in the intestine. Spleen and heart usually contained the next highest amount, and muscle and kidney had lower amounts. Dosed tocochromanols were never found in the brain over the $24 \mathrm{~h}$ period; traces of dietary $\alpha$-tocopherol were occasionally detected in the brain from rats which had been dosed with tocochromanols other than $\alpha$-tocopherol.

In most tissues the tocochromanols reached maximum levels $4^{-8} \mathrm{~h}$ after dosing, declining afterwards. The levels in the small intestine were maximal at $2 \mathrm{~h}$; in the muscle the maximum varied for each tocochromanol but the retention seemed to be better than in other tissues. When the results were expressed as $\mu \mathrm{g} / \mathrm{g}$ lipid, the distribution patterns followed essentially those produced when the results were expressed as $\mu \mathrm{g} / \mathrm{g}$ tissue.

In order to compare the absorption of the tocochromanols with each other, the results were expressed as percentage of the dose recovered (Fig. I). In the liver the relative order of uptake $4 \mathrm{~h}$ after dosing (the maximum for each tocochromanol) was: $\alpha \mathrm{T}>\alpha \mathrm{T}_{3}>\beta \mathrm{T}>\gamma \mathrm{T}>\delta \mathrm{T}>\beta \mathrm{T}_{3}>\gamma^{\prime} \mathrm{T}_{3}>\delta \mathrm{T}_{3}$. All the tocopherols were more effectively absorbed than their corresponding tocotrienols. The relative order of uptake in both series of compounds in terms of methyl group arrangement was $\alpha>\beta>\gamma>\delta$.

The complete relative order of uptake was not always the same in other tissues as that in the liver. In heart, muscle and kidney the tocotrienols were found in amounts equal to and often greater than those of the corresponding tocopherols. In the spleen all tocotrienols were absent after $8 \mathrm{~h}$ after dosing, whilst all the tocopherols were still present at $24 \mathrm{~h}$; the uptake of $\alpha$-tocotrienol was considerably greater than that of the other tocochromanols. No comparative deductions can be made from the intestine values, and it is not clear whether these are genuine tissue levels or are elevated levels due to tocochromanol from the intestinal contents adsorbed on to the mucosal cells or not completely washed from the surface. The pattern of continually decreasing levels over the $24 \mathrm{~h}$ is similar to that which would be expected if the intestine+ contents was assayed over this time period.

Only enough $\delta$-tocotrienol was available to measure the levels in the tissues at one time interval, and $4 \mathrm{~h}$ after dosing was chosen because this was the time of maximum absorption for most of the other tocochromanols. The levels of $\delta$-tocopherol in the tissues were also measured only at $4 \mathrm{~h}$, except in the liver, to compare with the $\delta$ tocotrienol (see Table I). 


\section{DISCUSSION}

There appear to be some anomalies concerning the distribution of $\alpha$-tocopherol. From rats which had been dosed with $\alpha$-tocopherol it was not detected in the brain, in the kidney, in the spleen at 4 and $8 \mathrm{~h}$, or in the heart $24 \mathrm{~h}$ after dosing. This was surprising because $\alpha$-tocopherol was often detected in these tissues in the experiments where other tocochromanols were fed, and in many instances it was even detected in the brain. It was noticed, however, that, in the animals given $\alpha$-tocopherol, considerable amounts of $\alpha$-tocopherolquinone were present, particularly in the heart and spleen where maximum levels of 14.3 and $16.4 \mu \mathrm{g} / \mathrm{g}$ tissue were recorded respectively. It is possible that $\alpha$-tocopherol is converted into its quinone more extensively than are the other tocochromanols. Very little is known about the occurrence of the quinone forms of the other tocochromanols. Henninger \& Crane (Ig63) reported the presence in spinach chloroplasts of $\beta$ - and $\gamma$-tocopherolquinone, the levels being much less than that of $\alpha$-tocopherolquinone. The tocopherolquinone related to $\alpha$-tocotrienol, i.e. $\alpha$-tocotrienolquinone, has been found in Hevea brasiliensis (K. J. Whittle \& J. F. Pennock, unpublished, cited by Pennock, I966).

This work illustrates that selective barriers other than the intestinal wall affect tocochromanol distribution in the animal body, each tissue appearing to exert its own selection. This is particularly striking in the brain, where occasionally dietary $\alpha$ tocopherol was detected but none of the dosed tocochromanols were found in the $24 \mathrm{~h}$ period. This was probably due to the 'blood-brain' barrier.

In attempting to correlate biological potencies with tissue storage levels the retention of the tocochromanol must be taken into account. In the liver for example, the ratio of the amounts of $\alpha$-tocopherol and $\alpha$-tocotrienol is Ioo:85 $4 \mathrm{~h}$ after dosing, whilst at $24 \mathrm{~h}$ the ratio is $100: 7$, the $\alpha$-tocopherol being retained much more effectively than the tocotrienol. Ratios of biological potency as determined by tissue storage tests will therefore depend largely on the time interval which elapses between the animal's last meal and its subsequent death.

We are grateful to the Science Research Council for the support of C.K.P. during this work.

\section{REFERENCES}

Albrink, M. J. (1959-60). F. Lipid Res. I, 53.

Bunyan, J., McHale, D., Green, J. \& Marcinkiewicz, S. (196I). Br. F. Nutr. 15, 253.

Dunphy, P. J., Whittle, K. J. \& Pennock, J. F. (1965). Chemy Ind. p. 1217.

Emmerie, A. \& Engel, C. (1938). Nature, Lond. 142, 873 .

Green, J., Edwin, E. E., Bunyan, J. \& Diplock, A. T. (1960). Biochem. F. 75, 456.

Henninger, M. D. \& Crane, F. L. (1963). Biochemistry 2, I 168.

Pearson, C. K. \& Barnes, M. McC. (I968). Biochem. F. 110, 2 I P.

Pennock, J. F. (1966). Vitams Horm. 24, 307.

Society for Analytical Chemistry: Analytical Methods Committee (1959), Analyst, Lond. 84, 356. 